Tropical Journal of Pharmaceutical Research April 2017; 16 (4): 905-910

ISSN: $1596-5996$ (print); 1596-9827 (electronic)

(C) Pharmacotherapy Group, Faculty of Pharmacy, University of Benin, Benin City, 300001 Nigeria.

All rights reserved.

Available online at http://www.tjpr.org

Original Research Article

http://dx.doi.org/10.4314/tjpr.v16i4.23

\title{
Chemical composition and insecticidal properties of essential oil from aerial parts of Mosla soochowensis against two grain storage insects
}

\author{
Xu-bo Chen, Rui Chen, Zheng-rong Luo* \\ College of Ecology, Lishui University, No. 1 Xueyuan Road, Lishui City, Zhejiang Province, 323000, China \\ *For correspondence: Email: extra@lsu.edu.cn; Tel: +86-578-2271308; Fax: +86-578-2271308 \\ Received: 19 August 2016 \\ Revised accepted: 5 March 2017
}

\begin{abstract}
Purpose: To determine the insecticidal properties of essential oil from Mosla soochowensis aerial parts against two insect pests, Sitophilus zeamais and Tribolium castaneum.

Methods: Hydro-distillation of M. soochowensis was used to extract the essential oil. Gas chromatography/mass spectrometry (GC/MS) analysis was performed, and the contact (topical application) and fumigant toxicity (sealed space) of the essential oil were evaluated.

Results: Thirty-nine chemical compounds were identified by GC-MS analysis of $M$. soochowensis essential oil. The major components are $\beta$-caryophyllene (12.82\%), spatulenol (6.34\%), $\beta$-eudesmol (6.26\%), carvone (6.12\%), $\alpha$-thujone (5.12\%), $\gamma$-eudesmol (4.86\%), $\alpha$-cedrol $(4.23 \%)$, and $\alpha$ caryophyllene (4.04\%). The plant essential oil exerted contact toxicity against adults of $S$. zeamais and $T$. castaneum (median lethal concentration ( $L C_{50}$ ), 25.45 and $10.23 \mu \mathrm{g} /$ adult, respectively). Moreover, the essential oil exhibited pronounced fumigant toxicity towards adults of both species (LC $C_{50} 12.19$ and $10.26 \mathrm{mg} / \mathrm{L}$ air, respectively).

Conclusion: These results show that $M$. soochowensis essential oil can be used in development of safer and more natural and effective fumigants/insecticides for stored products.
\end{abstract}

Keywords: Mosla soochowensis, Contact toxicity, Sitophilus zeamais, Fumigant, Insecticide, Essential oil, Tribolium castaneum

Tropical Journal of Pharmaceutical Research is indexed by Science Citation Index (SciSearch), Scopus, International Pharmaceutical Abstract, Chemical Abstracts, Embase, Index Copernicus, EBSCO, African Index Medicus, JournalSeek, Journal Citation Reports/Science Edition, Directory of Open Access Journals (DOAJ), African Journal Online, Bioline International, Open-J-Gate and Pharmacy Abstracts

\section{INTRODUCTION}

Contamination and destruction of stored food products by insects is a major problem for manufacturers and consumers, as the cost of such events runs to millions of dollars annually. In China, Sitophilus zeamais (Motsch.), commonly known as the maize weevil, and Tribolium castaneum (Herbst), commonly called the red flour beetle, have destructive effects on stored grain products [1], and infestations are typically controlled by fumigation techniques [2]. However, excessive use of synthetic fumigants and insecticides has several detrimental effects, including but are not limited to insecticide resistance, environmental contamination, and damage to human health and other non-target organisms [2,3]. Research into alternative treatments has shown that essential oils and their constituents possess insecticidal properties against many stored-product insect pests [4-6]; therefore, these may be alternatives to currently used fumigants and insecticides.

Mosla soochowensis Matsuda (Family: Lamiaceae) is an annual plant distributed predominantly in Anhui, Jiangsu, Jiangxi, and Zhejiang Provinces in China [7]. The aerial parts 
of $M$. soochowensis are applied in Chinese folk medicine to cure the common cold, tonsillitis, abdominal pain, and heartburn, and are used in ointments to treat insect and centipede bites [7]. Previous phytochemical studies on $M$. soochowensis identified several flavonoids [8,9] and the chemical composition of its essential oil [10,11]. Nevertheless, a literature search revealed that the insecticidal effects of $M$. soochowensis essential oil on grain insects have not been reported. Therefore, this study aimed to determine the chemical composition of $M$. soochowensis and the effects of its essential oil on two insect species.

\section{EXPERIMENTAL}

\section{Plant material and extraction of essential oil}

First, in August 2013, we gathered $5 \mathrm{~kg}$ of fresh M. soochowensis aerial parts at the flowering stage from Lishui $\left(27.54{ }^{\circ} \mathrm{N}, 119.20^{\circ} \mathrm{E}\right)$, located in Zhejiang Province, China. Dr. Wang from Lishui Academy of Forestry, Zhejiang, assisted with identification, A voucher specimen (category no. Isxy2013008) was kept at the herbarium of College of Ecology, Lishui University, Zhejiang, China. Samples were cut into pieces with pruning shears, and $900 \mathrm{~g}$ was transferred to three $\mathrm{L}-$ round-bottom flasks, each containing $1500 \mathrm{~mL}$ of tap water. The mixtures were then boiled for 6-8 hours, and the steam distilled. Because the essential oil is highly volatile, it was collected in a flask, separated from the aqueous layer using $n$ hexane in a separation funnel, and stored at 4 ${ }^{\circ} \mathrm{C} . \mathrm{Na}_{2} \mathrm{SO}_{4}$ was used to dry the extract, and the solvent was removed using a vacuum rotary evaporator.

\section{Analysis of the essential oil}

M. soochowensis essential oil was analyzed by gas chromatography-mass spectrometry (GCMS) using a mass selective detector (Agilent $5973 \mathrm{~N}$ ) and a non-polar HP-5ms capillary column of $30 \mathrm{~m} \times 0.25 \mathrm{~mm}$ (film thickness, 0.25 $\mu \mathrm{m})$. The column temperature program was as follows: hold at $60{ }^{\circ} \mathrm{C}$ for $1 \mathrm{~min}$; increase to 180 ${ }^{\circ} \mathrm{C}$ at $10{ }^{\circ} \mathrm{C}$ per min; hold at $180{ }^{\circ} \mathrm{C}$ for $1 \mathrm{~min}$; increase to $280{ }^{\circ} \mathrm{C}$ at $20{ }^{\circ} \mathrm{C}$ per min; and hold at $280{ }^{\circ} \mathrm{C}$ for $15 \mathrm{~min}$. The injector temperature was $270{ }^{\circ} \mathrm{C}$. Samples $(1 \mu \mathrm{L}$ were diluted $1: 100$ portion with acetone) were instilled with 1:10 split ratio. Helium at a flow rate of $1.0 \mathrm{~mL}$ per min was used as the carrier gas. Spectra were scanned from 20 to $550 \mathrm{~m} / \mathrm{z}$ at 2 scans per second. Constituents were identified based on retention indices in the literature or data from our laboratory. The retention indices were estimated under identical operating conditions using a homologous series of $n$-alkanes $\left(\mathrm{C}_{8}-\mathrm{C}_{24}\right)$. Further identification was performed by comparing the mass spectra with those in the NIST 05 and Wiley 275 libraries or in the literature [12]. Relative percentages were calculated based on GC peak areas, and no correction factor was applied.

\section{Insects}

The insects used in this study were from laboratory-reared colonies maintained for $\geq 10$ years. $T$. castaneum adults were kept on wheat flour blended with yeast $(10: 1, \mathrm{w} / \mathrm{w})$ at $29-30{ }^{\circ} \mathrm{C}$ and $70-80 \%$ relative humidity, while $S$. zeamais adults were reared on whole hard wheat (12 - $13 \%$ moisture) under the same conditions. Adults insects used in this study had been growing for 2 weeks. All containers and petri dishes used were designed to prevent escape by the insects, and were coated with polytetrafluoroethylene (Fluon, Blades Biological, UK).

\section{Test of contact toxicity}

Liu and Ho [13] proposed a method for determining the contact toxicity of $M$. soochowensis essential oil. First, essential oil concentrations were evaluated. $n$-Hexane was used to serially dilute $M$. soochowensis essential oil to $3.5-10.0 \% \mathrm{v} / \mathrm{w}$ in six steps. A Burkard hand micro-applicator (Burkard Scientific, Uxbridge, UK) was used to apply $0.5 \mu \mathrm{L}$ aliquots to the dorsal thorax of the insects. Ten treated insects were transferred to a glass bottle $(25 \mathrm{~mL})$ in five replicates. $n$-Hexane was used as a negative control, and pyrethrum extract (25\% pyrethrin I and pyrethrin II, Fluka Chemie AG, Switzerland) as a positive control. The treated and control insects were kept in incubators (29$30{ }^{\circ} \mathrm{C}, 70-80 \%$ relative humidity) for $24 \mathrm{~h}$ without a food supply, and mortality was monitored. Insects were considered dead if they did not react to a gentle touch with a dissecting needle or did not walk during a $3 \mathrm{~min}$ examination.

\section{Fumigant toxicity bioassay}

Essential oil fumigant toxicity was confirmed using the method of Liu and Ho [13], with minor modifications. To determine suitable test concentrations of the essential oil, several rangefinding studies were conducted. $n$-Hexane was used to prepare six $M$. soochowensis essential oil solutions $(3.0$ - $15.0 \% \mathrm{v} / \mathrm{v})$ using Whatman filter paper (2 cm diameter) and a screw-capped glass vial $(2.5 \mathrm{~cm}$ diameter, $5.5 \mathrm{~cm}$ height, $24 \mathrm{~mL}$ 
volume). An aliquot of essential oil solution (10 $\mu \mathrm{L}$ ) was dropped onto filter paper in the cap of a glass vial. The cap was then replaced on the glass vial, which contained 10 unsexed insects, and closed to form an airtight chamber. nHexane was used as a control. The treated and control insects were kept in incubators (29-30 ${ }^{\circ} \mathrm{C}, 70-80 \%$ relative humidity) for $24 \mathrm{~h}$ without a food supply, and mortality was monitored. Insects were considered dead if they did not react to a gentle touch with a dissecting needle or did not walk during a 3 min examination.

\section{Statistical analysis}

Abbott's formula was applied to estimate corrected percent mortality. The PriProbit software ver. 1.6.3 was used to determine $L^{2} D_{50}$ and $\mathrm{LC}_{50}$ values and their $95 \%$ confidence intervals [14]. Samples with non-overlapping 95 $\%$ fiducial limits were regarded as significantly different.

\section{RESULTS}

The yellow yield of the essential oil was $0.05 \%$ ( $\mathrm{v} / \mathrm{w}$, based on a fresh sample), and the density of the concentrated essential oil was $0.91 \mathrm{~g} / \mathrm{mL}$. Thirty-nine major components $(98.40 \%$ of the total; Table 1) were quantified. The major chemical constituents were $\beta$-caryophyllene (12.82 \%), spatulenol (6.34 \%), $\beta$-eudesmol $(6.26 \%)$, carvone $(6.12 \%)$, a-thujone (5.12 \%), $\mathrm{y}$-eudesmol (4.86\%), a-cedrol (4.23\%), and $\alpha$ caryophyllene (4.04 \%) (Table 1). Sixteen constituents were sesquiterpenoids $(61.23 \%$ of the total), and 15 were monoterpenoids (28.65\%).

The M. soochowensis essential oil displayed contact toxicity against $S$. zeamais and $T$. castaneum adults ( $\mathrm{LC}_{50}$ values, 25.45 and 10.23 $\mu \mathrm{g} /$ adult, respectively; Table 2 ). It also showed pronounced fumigant toxicity against $S$. zeamais and $T$. castaneum adults ( $\mathrm{LC}_{50}$ values, 12.19 and $10.26 \mathrm{mg} / \mathrm{L}$ air, respectively; Table 2 ).

\section{DISCUSSION}

GC and GC-MS analyses revealed that $\beta$ caryophyllene, spatulenol, $\beta$-eudesmol, carvone, and $\alpha$-thujone were the major chemical constituents of the essential oil of the aerial parts of $M$. soochowensis. This differs from previous reports. The major components of $M$. soochowensis essential oil from Jiangsu Province, China, were carvacrol (44.66\%), $\rho$ cymene (16.23\%), y-terpinene (7.13\%), 1,8- cineole $(5.76 \%)$, and thymyl acetate (5.20 \%) [11].

However, the major constituents of the essential oil of the same plant from Zhejiang Province, China, were methyl eugenol (40.40\%), nerolidene $(11.00 \%)$, dihydrocarvone $(8.21 \%)$, bornene (8.02\%), and $\beta$-thujone (7.31\%) [10]. This suggests that the oil composition of these plants differs according to location and growth stage $[10,11]$. Thus, the composition of this essential oil must be standardized prior to its commercial use.

The $M$. soochowensis essential oil showed significant contact toxicity against both insect species. However, the toxic effect was weaker than that for the positive control (Table 2).

Methyl bromide (MeBr) showed pronounced fumigant toxicity against both species $\left(\mathrm{LC}_{50} 0.67\right.$ $\mathrm{mg} / \mathrm{L}$ for $S$. zeamais and $1.75 \mathrm{mg} / \mathrm{L}$ for $T$. castaneum) [13]. Compared with $\mathrm{MeBr}$, the fumigant toxicity of the essential oil against maize weevil and red flour beetle was 18- and 6fold lower, respectively.

However, M. soochowensis essential oil had similar or greater fumigant toxic effects on $S$. zeamais adults compared with other essential oils, such as those of Artemisia lavandulaefolia, A. sieversiana [15], A. vestita [16], Glycosmis parviflora [17], Illicium pachyphyllum, I. simonsii [18,19], Mallotus apelta [20], Ostericum grosseserratum and $O$. sieboldii [21,22]. However, the fumigant toxic effect of the essential oil against $S$. zeamais adults was weaker than that of essential oil from Blumea balsamifera leaves [23].

\section{CONCLUSION}

The findings suggest that $M$. soochowensis essential oil exerts contact and fumigant toxic effects on two species of grain insect, suggesting its potential as a natural fumigant for stored products. Development of viable alternatives to commercially used, synthetic compounds is important because of the spread of resistance to these pesticides and their environmental toxicity.

To best of our knowledge no study has assessed the effect of $M$. soochowensis essential oil on human health. However, because aerial parts of this plant are consumed in China as a traditional medicine, the threat to human health is likely low. Further work should include evaluation of its nonspecific toxic effects. 
Table 1: Major compounds of Mosla soochowensis essential oil

\begin{tabular}{|c|c|c|c|}
\hline Peak no. & Compound & Retention index & $(\%)$ \\
\hline & Monoterpenoids & & 28.65 \\
\hline 1 & $\alpha-P i n e n e^{\pi \pi}$ & 931 & 0.83 \\
\hline 2 & Sabinene & 975 & 2.56 \\
\hline 3 & $\beta$-Pinene & 981 & 1.15 \\
\hline 4 & o-Cymene & 1020 & 0.94 \\
\hline 5 & d-Limonene" & 1027 & 1.68 \\
\hline 6 & 1,8-Cineole" & 1031 & 2.99 \\
\hline 7 & Linalool & 1097 & 0.17 \\
\hline 8 & $\alpha$-Thujone & 1105 & 5.21 \\
\hline 9 & cis-Carveol & 1222 & 0.13 \\
\hline 10 & Thymol methyl ether & 1235 & 0.39 \\
\hline 11 & Carvone & 1238 & 6.12 \\
\hline 12 & Thymol $^{\pi x}$ & 1294 & 3.72 \\
\hline 13 & Carvacrol & 1304 & 1.58 \\
\hline 14 & Thymol acetate & 1362 & 0.66 \\
\hline \multirow[t]{2}{*}{15} & Carvacrol acetate & 1367 & 0.52 \\
\hline & Sesquiterpenoids & & 61.23 \\
\hline 16 & Copaene & 1375 & 3.72 \\
\hline 17 & a-Bourbonene & 1409 & 1.48 \\
\hline 18 & $\beta$-Ylangene & 1423 & 0.99 \\
\hline 19 & $\beta$-Caryophyllene & 1428 & 12.82 \\
\hline 20 & a-Bergamotene & 1430 & 2.83 \\
\hline 21 & a-Caryophyllene" & 1456 & 4.04 \\
\hline 22 & trans-a-Farnesene & 1486 & 1.12 \\
\hline 23 & $\beta$-Bisabolene & 1506 & 3.63 \\
\hline 24 & $\delta$-Cadinene & 1523 & 1.81 \\
\hline 25 & $\beta$-Sesquiphellandrene & 1525 & 1.03 \\
\hline 26 & Spathulenol" & 1578 & 6.34 \\
\hline 27 & Caryophyllene oxide & 1584 & 3.56 \\
\hline 28 & $a-C e d r o l$ & 1598 & 4.23 \\
\hline 29 & y-Eudesmol & 1621 & 4.86 \\
\hline 30 & $\beta$-Eudesmol & 1650 & 6.26 \\
\hline \multirow[t]{2}{*}{31} & $\beta$-Bisabolol & 1673 & 2.51 \\
\hline & Phenylpropanoids & & 7.71 \\
\hline 32 & Methyl eugenol & 1403 & 1.82 \\
\hline 33 & Myristicin & 1513 & 2.18 \\
\hline 34 & Elemicin & 1558 & 0.41 \\
\hline 35 & Asarone" & 1645 & 1.58 \\
\hline \multirow[t]{2}{*}{36} & Apiole & 1682 & 1.72 \\
\hline & Others & & 0.66 \\
\hline 37 & Benzaldehyde & 960 & 0.46 \\
\hline 38 & Acetophenone & 1065 & 0.21 \\
\hline \multirow[t]{2}{*}{39} & Octyl acetate & 1215 & 0.14 \\
\hline & Total identified & & 98.40 \\
\hline
\end{tabular}

${ }^{*} R l$, retention index; "Identification by co-injection of authentic compounds

Table 2: Contact and fumigant toxicity of Mosla soochowensis essential oil against adults of S. zeamais (SZ) and T. castaneum (TC)

\begin{tabular}{|c|c|c|c|c|c|}
\hline Toxicity & Insect & Treatment & $\mathrm{LC}_{50}(95 \% \mathrm{Cl})$ & Slope \pm SD & Chi-squared $\left(x^{2}\right)$ \\
\hline \multirow{4}{*}{$\begin{array}{l}\text { Contact } \\
\text { toxicity } \\
\text { ( } \mu \text { g/adult) }\end{array}$} & \multirow{2}{*}{ SZ } & M. soochowensis & 25.45 (23.13-26.92) & $3.08 \pm 0.29$ & $13.43^{\mathrm{a}}$ \\
\hline & & Pyrethrum extract & 4.29 (3.86-4.72) & - & - \\
\hline & \multirow{2}{*}{ TC } & M. soochowensis & $10.23(9.34-11.09)$ & $3.23 \pm 0.31$ & $10.11^{\mathrm{a}}$ \\
\hline & & Pyrethrum extract & $0.36(0.32-0.41)$ & - & - \\
\hline \multirow{4}{*}{$\begin{array}{l}\text { Fumigant } \\
\text { (mg/L) }\end{array}$} & \multirow[b]{2}{*}{ SZ } & M. soochowensis & $12.19(12.04-13.29)$ & $3.45 \pm 0.32$ & $11.27^{\mathrm{a}}$ \\
\hline & & $\mathrm{MeBr}^{* *}$ & 0.67 & - & - \\
\hline & \multirow{2}{*}{$\mathrm{TC}$} & M. soochowensis & $10.26(9.32-11.26)$ & $3.18 \pm 0.28$ & $9.32^{\mathrm{a}}$ \\
\hline & & $\mathrm{MeBr}^{* \star}$ & 1.74 & - & - \\
\hline
\end{tabular}

Liu and Ho [13]; ${ }^{a} p<0.05$ 


\section{DECLARATIONS}

\section{Acknowledgement}

This work was supported by Scientific Research Fund of Zhejiang Provincial Education Department (Grant no. Y201431160), Zhejiang Provincial Natural Science Foundation of China (Grant no. LY14C030003) and the ecology which is first class discipline of Zhejiang Province. The authors thank Dr. Wang JF from Lishui Academy of Forestry, Zhejiang Province, China for identification of the medicinal herb studied.

\section{Conflict of Interest}

No conflict of interest associated with this work.

\section{Contribution of Authors}

The authors declare that this work was done by the authors named in this article and all liabilities pertaining to claims relating to the content of this article will be borne by them.

\section{Open Access}

This is an Open Access article that uses a funding model which does not charge readers or their institutions for access and distributed under the terms of the Creative Commons Attribution License (http://creativecommons.org/licenses/by/ 4.0) and the Budapest Open Access Initiative (http://www.budapestopenaccessinitiative.org/rea d), which permit unrestricted use, distribution, and reproduction in any medium, provided the original work is properly credited.

\section{REFERENCES}

1. Liu ZL, Goh SH, Ho SH. Screening of Chinese medicinal herbs for bioactivity against Sitophilus zeamais Mostchulsky and Tribolium castaneum (Herbst). J Stored Prod Res 2007; 43: 290-296.

2. Zettler JL, Arthur FH. Chemical control of stored product insects with fumigants and residual treatments. Crop Prot 2000; 19: 577-582.

3. Regnault-Roger C, Vincent C, Arnason JT. Essential oils in insect control: low-risk products in a high-stakes world. Annu Rev Entomol 2012; 57: 405-424.

4. Chu SS, Hu JF, Liu ZL. Composition of essential oil of Chinese Chenopodium ambrosioides and insecticidal activity to maize weevil, Sitophilus zeamais. Pest Manag Sci 2011; 67: 714-718

5. Zhang JS, Zhao NN, Liu QZ, Liu ZL, Du SS, Zhou L, Deng ZW. Repellent constituents of essential oil of Cymbopogon distans aerial parts against two stored- product insects. J Agric Food Chem 2011; 59: 99109915.

6. Li HY, Liu XC, Chen XB, Liu QZ, Liu ZL. Chemical composition and insecticidal activities of the essential oil of Clinopodium chinense (Benth.) Kuntze. aerial parts against Liposcelis bostrychophila Badonnel. J Food Prot 2015; 78: 1870-1874.

7. Editorial Committee of Flora of China of Chinese Academy of Sciences. Flora Reipublicae Popularis Sinicae, Science Press, Beijing, China. 1977; 66: 292293. http://www.efloras.org/florataxon.aspx?flora_id=2\& taxon_id=200019870

8. Zheng SZ, Fu ZS, Yang CX, Sun LP, Shen XW. Two new flavonoids from Mosla soochouensis Matsuda. Indian $J$ Chem 1998; 37B: 1078-1080.

9. Wang $Q$, Terreaux $C$, Marston A, Tan RX, Stoeckli-Evans $H$, Hostettmann K. A new 2-hydroxyflavanone from Mosla soochouensis. Planta Med 1999; 65: 729-731.

10. Chen J, WU QF. Study on extraction methods of volatile oil from Mosla soochowensis. J Chin Med Materials 2005; 28: 823-825.

11. Tan XH, Chao JG, Li W. Pharmacognostical identification of Chinese drug Wuxiangcao (Mosla soochowensis). J Chin Med Materials 1998; 21: 337-339.

12. Adams RP. Identification of essential oil components by gas chromatography-mass spectrometry. 4th ed. Allured Publishing Corporation, Carol Stream, USA, 2007.

13. Liu ZL, Ho SH. Bioactivity of the essential oil extracted from Evodia rutaecarpa Hook $f$. et Thomas against the grain storage insects, Sitophilus zeamais Motsch. and Tribolium castaneum (Herbst). J Stored Prod Res 1999; 35: 317-328.

14. Sakuma M. Probit analysis of preference data. Appl Entomol Zool 1998; 33: 339-347.

15. Liu ZL, Liu QR, Chu SS, Jing GH. Insecticidal activity and chemical composition of the essential oils of Artemisia lavandulaefolia and Artemisia sieversiana from China. Chem Biodiv 2010; 7: 2040-2045.

16. Chu SS, Liu QR, Liu ZL. Insecticidal activity and chemical composition of the essential oil of Artemisia vestita from China against Sitophilus zeamais. Biochem Syst Ecol 2010; 38: 489-492.

17. Liu ZL, Yang K, Bai PH, Zhou L, Liu SL, Liu QZ. Gas chromatography-mass spectrometric analysis of essential oil of aerial parts of Glycosmis parviflora (Sims) Little (Rutaceae). Trop J Pharm Res 2014; 13: 275-280.

18. Chu SS, Liu SL, Jiang GH, Liu ZL. Composition and toxicity of essential oil of Illicium simonsii Maxim (Illiciaceae) fruit against the maize weevils. Rec Nat Prod 2010; 4: 205-210.

19. Liu P, Liu XC, Dong HW, Liu ZL, Du SS, Deng ZW. Chemical composition and insecticidal activity of the essential oil of Illicium pachyphyllum fruits against two grain storage insects. Molecules 2012; 17: 1487014881.

20. Liu XC, Chen XB, Liu ZL. Gas chromatography-mass spectrometric analysis and insecticidal activity of

Trop J Pharm Res, April 2017; 16(4): 909 
essential oil of aerial parts of Mallotus apelta (Lour.) Muell.-Arg. (Euphorbiaceae). Trop J Pharm Res 2014; 13: 1319-1326.

21. Chu SS, Jiang GH, Liu ZL. Chemical composition and insecticidal activity of the essential oil of Ostericum grosseserratum (Maxim.) Kitag. Trop J Pharm Res 2013; 12: 99-103.
22. Liu ZL, Chu SS, Jiang GH. Insecticidal activity and composition of essential oil of Ostericum sieboldii (Apiaceae) against Sitophilus zeamais and Tribolium castaneum. Rec Nat Prod 2011; 5: 74-81.

23. Chu SS, Du SS, Liu ZL. Fumigant compounds from the essential oil of Chinese Blumea balsamifera leaves against the maize weevil (Sitophilus zeamais). J Chem 2013; doi:10.1155/2013/289874. 